RESEARCH NOTE

\section{Adjective placement in simultaneous bilinguals (German-Italian) and the concept of cross-linguistic overcorrection*}

\author{
TANJA KUPISCH \\ Lunds Universitet/University of Hamburg
}

(Received: December 31, 2012; final revision received: June 10, 2013; accepted: June 18, 2013; first published online: 20 August 2013)

Cross-linguistic influence (CLI) has been claimed to occur under the conditions of structural overlap, interfacing, syntactic complexity and language dominance. This study tested adjective placement in the Italian of 19 adult German-Italian simultaneous bilinguals, comparing naturalistic and experimental data. The results show no CLI from German, although the conditions for CLI are given. Instead, bilingual adults tend to overuse a structure that is unique to Italian, unlike bilingual children in previous studies. However, they do so only in the experimental data. In order to account for this, I introduce the concept of CROSS-LINGUISTIC OVERCORRECTION in contrast to CROSS-LINGUISTIC INFLUENCE.

Keywords: adjective placement, Italian, simultaneous bilingualism, cross-linguistic overcorrection, crosslinguistic influence

\section{Introduction}

It has often been observed that bilingual (2L1) grammars are more variable than their monolingual counterparts. The most common explanation for this variation is the existence of cross-linguistic influence (CLI) (also: "crosslinguistic transfer" or "transfer"). Since CLI is not found to the same extent in all speakers and all domains of grammar, it has been proposed to depend on certain qualitative and quantitative factors.

Previous studies have identified at least three conditions under which a particular phenomenon is vulnerable to CLI. The first one is that the phenomenon is located at an interface, either between syntax and pragmatics (Hulk \& Müller, 2000; Sorace, 2011) or between syntax and semantics (Montrul \& Ionin, 2010; Sorace \& Serratrice, 2009). Another determinant is the existence of syntactic ambiguity or "partial overlap" on the surface structure (Döpke, 1998; Müller, 1998). Syntactic ambiguity is present if one language has only one possible construction with respect to a particular phenomenon (e.g. adjectives follow the noun) and the

* This research was funded by the German Science Foundation as part of SFB 538 in Hamburg. Thanks to Giulia Bianchi, Roberta Colonna Dahlmann, Timm Lehmberg, Cristina Pierantozzi, Antonio Tomasello and all participants for supporting the data collection and analysis. I also wish to thank Merete Anderssen, Anna Cardinaletti, Giuliana Giusti, Marianne Gullberg, Ana Pérez-Leroux, Mihaela Pirvulescu, Yves Roberge, Marit Westergaard, Frank Zenker and three anonymous reviewers for their comments. Special thanks to Joost van de Weijer for his assistance with the statistics. other language has two possible constructions for the same phenomenon, one being shared by both languages (e.g. adjectives precede or follow the noun). Hulk and Müller (2000) considered partial overlap and the syntaxpragmatics interface being involved as jointly necessary for the occurrence of CLI. Additionally, or alternatively, CLI may be determined by syntactic complexity (e.g. Jakubowicz, 2002: Strik \& Pérez-Leroux, 2011). All three factors are also claimed to be predictive of the DIRECTION of CLI. Specifically, a phenomenon in a language A is more likely to be subject to cross-linguistic influence if:

- it involves an interface,

- it can be expressed with two different syntactic structures in language A, while language B exhibits only one of the two structures,

- its syntactic derivation in language $\mathrm{A}$ is more complex than that of the corresponding structure in language $B$.

The above three can be considered qualitative factors, because it is the structure of the phenomenon that determines its vulnerability. In other words, it is crucial whether or not the phenomenon involves an interface, is ambiguous and derivationally complex. ${ }^{1}$

\footnotetext{
1 There is no agreement, so far, on whether these factors are necessary or sufficient in order for CLI to occur. It is likely that, individually, they are neither necessary nor sufficient. Although this discussion needs to be pursued in the future, it is less important for the present paper, which shows that even if all factors are given, the result may not be CLI.
} 
According to many scholars, another factor determining CLI is language dominance, the assumption being that the stronger language influences the weaker language (e.g. Kupisch, 2007; Serratrice, Sorace, Filiaci \& Baldo, 2009; Yip \& Matthews, 2007). I take language dominance to be a QUANTITATIVE FACTOR, as it may or may not occur, and if it does, it can be pronounced to different extents. Unlike qualitative factors, dominance does not predict that a particular STRUCTURE is subject to CLI due to its ambiguity or complexity. Instead, it is a particular LANGUAGE that undergoes CLI, regardless of its ambiguity or complexity. Qualitative and quantitative factors are not mutually exclusive (Kupisch, 2007, 2012).

In this paper, I would like to question the assumption, implicit in most of the literature, that interfacing, ambiguity, complexity and dominance necessarily lead to CLI. Instead, I propose that the previously identified determinants of CLI can also result in what I refer to as "cross-linguistic overcorrection" (CLO), at least in ADULT bilinguals. Put simply: in cases of extreme vulnerability resulting from variation, complexity, the need to combine information from different modules and performance under time pressure, bilinguals show a tendency to overstress WHAT IS DIFFERENT rather than WHAT IS COMMON in their two languages. In support of this idea I present data from 19 GermanItalian adult simultaneous bilinguals. In what follows, I introduce adjective placement in Italian, making reference to German when relevant, and motivating why CLI is expected. Section 3 summarizes previous research on the acquisition of adjective placement, raising open questions. Section 4 introduces the participants and presents the two studies. The paper concludes with discussion and conclusions in Sections 5 and 6.

\section{Adjective placement in German and Italian}

Attributive adjectives occur prenominally $(\operatorname{Adj}-\mathrm{N})$ in German. By contrast, the canonical and more frequent position for Italian adjectives is postnominal (N-Adj) (Cardinaletti \& Giusti, 2010):

(1) a. Ge. ein grüner Rock. vs. *ein Rock grüner b. It. *una verde gonna vs. una gonna verde a skirt green a green skirt

However, some Italian adjectives can be placed before or after the noun. Often, each position is associated with a different meaning. For example, postnominal alto "high" in (2a) refers to size, while prenominal alto in (2b) refers to a value. Similarly, in (3a), povero means "without property", while the prenominal position in (3b) suggests that the boy referred to is "pitiful", while he may be rich or poor. In order to determine the appropriate position of adjectives with variable position, as in (2) and (3), the context is relevant. For example, in the context of a boy who cannot afford to buy food, (3a) is more likely to be chosen, while in the context of a rich boy with no friends, (3b) is more likely to be chosen.

(2) a. un ufficiale alto an officer high "an officer who is tall"

b. un alto ufficiale "an officer high in rank"

(3) a. un ragazzo povero
a boy poor
"a boy without money"
b. un povero ragazzo
"a pitiful boy who may or may not have money"

Some adjectives occur before or after the noun with no change in meaning, e.g. bello "nice", vecchio "old", giovane "young" and nuovo "new".

(4) a. una macchina bella / una bella macchina a car nice

b. una macchina nuova / una nuova macchina a car new

c. una donna giovane / una giovane donna a woman young

Some adjectives appearing pre- and postnominally have only one possible reading in the prenominal position, as in (5a) below, but two possible readings in the postnominal position, as in (5b). The DIRECT MODIFICATION reading, in (5a) and (5bi), is possible with both orders, while the INDIRECT MODIFICATION reading in (5bii) is unique to postnominal adjectives (Cardinaletti \& Giusti, 2010; Cinque, 2010). In indirect modification, the adjective functions as a reduced relative clause with a restrictive interpretation.

(5) a. una mia grande amica

(non-ambiguous)

$$
\text { a my big friend }
$$

"a close friend of mine"

b. una mia amica grande (ambiguous)

i. "a close friend of mine"

ii. "a friend of mine who is old(er than I)/tall/big"

As for syntactic derivation, descriptive adjectives are merged in the specifier of functional projections in the $\mathrm{D}$ (eterminer) $\mathrm{P}$ (hrase) (Cinque, 1994). The base position of the $\mathrm{A}$ (djective) $\mathrm{P}$ (hrase)s is the same in Germanic and Romance, and the prenominal vs. postnominal position

\footnotetext{
2 Here, some speakers claim to perceive a subtle difference in meaning depending on the position of the adjective. Within a given context, one of the options may become unnatural or even unacceptable for stylistic or frequency-related reasons.
} 
can be accounted for with NP-movement across the adjective (Cinque, 2010, among many others).

(6)

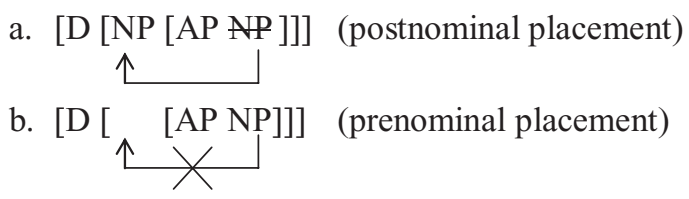

The assumption that complexity increases with each movement step implies that postnominal placement is more complex than prenominal placement. There are some rare exceptions where prenominal placement can involve further movement steps (see (9b) below).

The syntactic hierarchy in (7) shows a simplified representation of Cinque's $(1994,2010)$ proposal, adapted from Cardinaletti and Giusti (2010).

(7) det $>$ value $>$ size $>$ shape $>$ colour

$$
\begin{array}{ll}
\quad \mathrm{N}(\mathrm{P})_{\text {opt }} & \mathrm{N}(\mathrm{P})_{\text {opt }} \mathrm{N}(\mathrm{P})_{\text {opt }} \mathrm{N}(\mathrm{P})_{\text {opt }} \\
>\text { nationality }>\text { classificatory } \\
\mathrm{N}(\mathrm{P})_{\text {obl }} \quad \mathrm{N}(\mathrm{P})_{\text {obl }}
\end{array}
$$

Italian nouns obligatorily cross over classificatory and nationality adjectives, which must therefore be in postnominal position:

(8) a. la scuola materna/*la materna scuola the school primary

b. la scuola italiana/*1'italiana scuola the school Italian

As shown in (2) and (3) above, movement over size and value adjectives is optional. For color and shape adjectives movement is optional too (see (9)), but the prenominal order in (9b) is restricted to poetic contexts. According to Giusti (2006), such readings involve movement to the left periphery of the DP, where syntax and pragmatics interface.

(9) a. le colline verdi della Toscana the hills green of.the Tuscany

b. le verdi colline della Toscana

The syntactic derivation of DPs with adjectives in the same surface position may differ according to their meanings (Cinque, 2010). The details are not relevant here and depend on the syntactic analysis adopted (see Rizzi, Arnaus Gil, Repetto, Müller \& Müller, 2013, for discussion). The important point for the present paper is that one can find several reasons why the placement of Italian adjectives in German-Italian bilinguals should be subject to influence from German:

- The adjective position with respect to the noun varies, depending on the context.

- Some Italian adjective-noun strings look like "German syntax".
- The syntactic derivation of adjective phrases is generally more complex in Italian (involving more movement steps) and may involve the left periphery of the DP.

\section{The acquisition of adjective placement in Italian: Some open questions}

While monolingual Italian-learning children use Adj-N and N-Adj orders correctly from early on (Cardinaletti \& Giusti, 2010), bilingual children acquiring a Germanic and a Romance language simultaneously may pass through a stage of non-targetlike placement, especially in their Romance language.

Volterra \& Taeschner (1978, p. 322) already reported several instances of Adj-N strings (e.g. glande pesciolino "big fish") in the Italian of two German-Italian children. The authors proposed a "fused syntax", and interpreted Adj-N strings as usage of "German syntax" in Italian. However, they failed to point out that the majority of these instances included adjectives such as bello "nice", buono "good", grande "big", grosso "big", which can, in fact, occur prenominally in Italian. Moreover, some of their examples may involve copula omissions, which would mean that the adjectives are in predicative position and thus appropriately placed. For example, when Lisa produced buono la mela "good the apple", she might have intended è buona, la mela "is good the apple".

More convincing evidence for CLI has been provided by Bernardini (2003). She reported longitudinal data from a Swedish-Italian bilingual boy, born and raised in Sweden, whose use of postnominal adjectives in Italian was delayed. Similarly, Rizzi et al. (2013) found problems with the postnominal order in the spontaneous speech of bilingual children acquiring Italian and German (ages from $1 ; 7$ to $5 ; 7)$. Most instances of incorrect use in Italian involved overuse of the prenominal position (ibid., p. 141).

In accordance with the above studies, Nicoladis (2006) has shown that, in elicited production, English-French bilingual children used the prenominal order in French more often than their monolingual French peers. At the same time, however, she also found a non-negligible number of reversals in which the postnominal position was used although the prenominal position would have been correct. Overuse of the postnominal position is not predicted if overlap, interfacing and complexity determine CLI. The higher number of postnominal adjectives in her study, as compared to Bernardini (2003) and Rizzi et al. (2003), could be due to different factors, including age range, language combination and method (naturalistic vs. elicited data). 
Table 1. Overview of participants.

\begin{tabular}{lll}
\hline \hline & 2L1 strong Italian & 2L1 weak Italian \\
\hline Number of participants & 8 & 11 \\
Predominant place of residence before 19;0 & Italy & Germany \\
Language used more frequently before 19;0 & Italian & German \\
Language used more frequently at the time of testing & Italian* & German \\
Age & 18-38 (mean: 27) & 19-39 (mean: 28) \\
\hline
\end{tabular}

* One exception; see text.

Previous research leaves open a few questions. Since no end state data on adjective placement in bilinguals has been provided so far, one may ask whether the overuse patterns typical of bilingual children persist through adulthood. Furthermore, no study has compared adjective placement in Italian bilinguals with respect to language dominance and with respect to methods, i.e. naturalistic as compared to experimental data. These observations raise the following questions:

(i) Do adult bilingual speakers of Italian, like bilingual children, show a tendency to overuse the prenominal position where the postnominal one is required, if Italian is in contact with a language showing only prenominal placement?

(ii) Are there differences between bilinguals who acquired Italian in Italy and bilinguals who acquired Italian in Germany?

(iii) Is variation in adjective placement dealt with differently in experimental and naturalistic contexts?

\section{Adjective study}

Two studies with the same groups of participants were undertaken, one based on naturalistic data, one based on a timed acceptability judgment task (AJT).

\subsection{Participants}

Data were collected in the project E11 at the Research Centre of Multilingualism in Hamburg. The naturalistic data are part of the HABLa corpus (Hamburg Adult Bilingual Language; see Kupisch, Barton, Bianchi \& Stangen, 2012). The participants were 19 adult GermanItalian simultaneous bilingual (2L1) speakers, born and raised in binational families: eight grew up in Italy and 11 grew up in Germany. All had one German-speaking and one Italian-speaking parent, who used their respective languages with them.

The $112 \mathrm{~L} 1 \mathrm{~s}$ who grew up in Germany (2L1 weak Italian) meet the definition of heritage speakers (of Italian) in the sense of Rothman (2009, p. 156): Italian was acquired on the basis of an interaction with naturalistic input at home and it was not the language of the national (here: German) society. Before the age of 19, participants in this group had spent only short periods in Italy, usually between three and six weeks during summer vacations. After the age of 19, most of them $(n=6)$ continued to stay in Germany, while the others spent one or several years in Italy, and then returned to Germany. During childhood and adolescence, all attended monolingual German schools, but four had weekly afternoon classes, where they read and wrote Italian. According to self-reports, their parents always used their respective languages with them; only two reported decreasing use of Italian at home over the years. While the data were collected, three participants used Italian very frequently (within the family AND during work), five used it frequently (within the family OR at work), and three had very few occasions to use the language. Use of German was predominant for all speakers, and it was also the language that most speakers $(\mathrm{n}=7)$ felt most comfortable using. Four speakers felt equally comfortable using both languages. All but two had a foreign accent in Italian.

For the eight $2 \mathrm{~L} 1 \mathrm{~s}$ who grew up in Italy (2L1 strong Italian), GERMAN can be considered the heritage language. In this group, five speakers attended a GermanItalian bilingual school, and all but two reported continuous use of both languages at home during childhood. Speakers in this group had never spent more than 6 months in Germany. At the time of testing, they used German comparatively little, felt more confident using Italian and had a foreign accent when speaking German. One participant constitutes an exception. He had moved to Germany at the age of 21 and had been living there for 17 years.

Table 1 provides an overview of the participants.

\subsection{Naturalistic data}

\section{Methods}

The first study was based on naturalistic speech data. The interviews were about 30 minutes long and loosely prestructured, dealing with topics such as the participants' linguistic biography, cultural stereotypes, food, recent movies or books. The data were transcribed and searched for all instances of attributive adjectives. 
Adjectives were coded in terms of pre- and postnominal placement and appropriateness of the adjective position (the latter was checked independently by three native speakers of Italian). The following adjectives were excluded: Possessive adjectives (e.g. mio "my"), quantifier-like adjectives (e.g. nessuno "no", vari "several"), participles (e.g. cose scritte "written things"), adjectives which were part of names of regions, dishes and well-known movies or books (e.g. Bassa Sassonia "Lower Saxony", Spaghetti Carbonara, L'ultimo bacio "The last kiss", I promessi sposi "The betrothed").

\section{Results}

The $2 \mathrm{~L} 1 \mathrm{~s}$ with Italian as the stronger language produced 696 attributive adjectives, 237 (34.1\%) in prenominal and 459 in postnominal position. Of all adjectives $104(14.9 \%)$ were part of complex constructions (i.e. coordinated with other adjectives or modified by adverbs). These were relatively more frequent with postnominal $(\mathrm{n}=$ $83)$ than with prenominal adjectives $(\mathrm{n}=21)$. Incorrect adjectives placement order occurred only twice $(0.3 \%)$, once prenominally and once postnominally, and there is one case for which one coder had a different preference for stylistic reasons but considered both positions acceptable.

The heritage speakers of Italian produced 691 attributive adjectives, 249 (36\%) prenominally and 442 postnominally. Comparatively fewer adjectives $(\mathrm{n}=$ 91, 13.2\%) were part of complex constructions, and these were more frequent postnominally $(\mathrm{n}=78)$ than prenominally $(\mathrm{n}=13)$. Only 10 adjectives $(1.4 \%)$ were placed incorrectly.

A mixed model regression analysis was carried out to determine whether the number of incorrectly placed adjectives differed significantly between the two groups. The contrast was not significant $(\mathrm{B}=-1.82, \mathrm{SE}=1.17$, $\mathrm{z}=-1.56, p=.12$ ). Table 2 provides an overview of the analysis of the naturalistic data.

All instances of incorrect placement in the $2 \mathrm{~L} 1 \mathrm{~s}$ with Italian as their weaker language involved prenominal placement where postnominal placement was required, see (10).

(10) a. questi sono i mie i miei viaggi grandi. these are the my the my trips big

b. lui la moglie e una piccola una

he the wife and a small a

piccola figlia di sette otto anni.

small girl of seven eight years

For another 14 adjectives (2.03\%), one coder remarked that the adjective sounded acceptable in both positions, although she would have preferred a different position for stylistic or lexical reasons (six times for adjectives in prenominal position and eight times for adjectives in postnominal position). For example, with respect to cloth, buon gusto "good taste" is preferred, while with respect to food gusto buono "taste good" is preferred but buon gusto is also possible (compare (11a)). In other cases, e.g. (11b), the coder could not explain her preference but suspected that one position sounded more natural for reasons related to frequency.

(11) a. mi piace che la verdura ha un un I like that the vegetable has a a buon gusto ... good taste

b. ... tra le di- diverse civiltà
among the different cultures
che esistono sul mondo $\ldots$
that exists on.the world

As for adjective types, the $2 \mathrm{~L} 1 \mathrm{~s}$ with Italian as the stronger language used 44 different adjectives in prenominal position (type/token ratio: 5.39) and 197 different adjectives in postnominal position (type/token ratio 2.34), while 18 types occurred in both positions. ${ }^{3}$

3 Determiner-like adjectives (altro "other" and ordinal numbers), nationality adjectives and colors were each counted as one single type.

Table 2. Overview of adjective placement in Italian as weaker and as stronger language (naturalistic data).

\begin{tabular}{lll}
\hline \hline & 2L1 strong Italian & 2L1 weak Italian \\
\hline Total number of attributive adjectives & 696 & 691 \\
Number of prenominal adjectives & $237(34.1 \%)$ & $249(36 \%)$ \\
Adjectives in complex constructions & $102(14.7 \%)$ & $91(13.2 \%)$ \\
Incorrect placement & $2(0.3 \%)$ & $10(1.4 \%)$ \\
Type-token ratio of prenominal adjectives & 5.39 & 7.1 \\
Type-token ratio in postnominal adjectives & 2.34 & 2.84 \\
\hline \hline
\end{tabular}


The heritage speakers of Italian used comparatively fewer adjective types both prenominally $(\mathrm{n}=35$, type/token ratio: 7.1 ) and postnominally $(\mathrm{n}=162$, type/token ratio 2.84). The number of adjectives that occurred in both positions was comparatively higher $(\mathrm{n}=24)$.

The distribution of adjectives that occurred both preand postnominally (bello "nice", buono "good", classico "classic", diverso "different", famoso "famous", grande "big", migliore "better", nuovo "new", tipico "typical", unico "only/unique", vecchio "old") was similar in the two groups. The $2 \mathrm{~L} 1 \mathrm{~s}$ with Italian as the stronger language produced 95 tokens, of which $62(65.3 \%)$ were prenominal; the heritage speakers produced 103 tokens, of which $68(66 \%)$ were prenominal. Use of the adjective piccolo "small" was noticeably different in the two groups. The $2 \mathrm{~L} 1 \mathrm{~s}$ with Italian as the stronger language never used it prenominally, while the heritage speakers did so often, and 7 out of 29 times incorrectly (see the examples in (12), and especially (12b), which indicates the speaker's uncertainty about the position).

(12) a. quando era un piccolo bambino ... when was.he a small boy

b. con le piccole bambine piccole si può with the small girls small one can andare ... al mare

go to.the sea

In summary, the $2 \mathrm{~L} 1 \mathrm{~s}$ who grew up in Italy made practically no errors, while the heritage speakers of Italian produced a few prenominal adjectives where postnominal adjectives were required, but the difference between the two groups was not significant. The two groups also showed a similar distribution of pre- and postnominal uses. The heritage speakers used fewer adjective types and a few adjective-noun strings which monolinguals found acceptable but which they dispreferred.

\subsection{Experimental data}

\section{Method}

In this part of the study the $2 \mathrm{~L} 1 \mathrm{~s}$ were tested in a bi-modal acceptability judgment task (AJT). They were instructed to read and listen to written sentences in a powerpoint presentation. The aural stimuli were previously recorded by a native speaker of Italian. Participants were told to repeat the sentence orally if it was acceptable and to correct it if they judged it faulty. Response time was limited and corresponded to three times the duration of the test sentence produced by a native speaker of Italian.

The AJT contained a total of 148 items and took about 45 minutes. It primarily tested gender and article use besides adjective placement. All sentences were intensively piloted. For all adjectives in the final test version, there was only one possible order, according to independent judgments of 15 monolingual Italian speakers.

\section{Stimuli}

There were 44 stimuli targeting the placement of attributive adjectives. All adjectives were embedded in a sentence. Of these sentences, 22 were grammatical and 22 ungrammatical; 22 contained prenomominal adjectives, 21 postnominal ones, and one a combination of a pre- and a postnominal adjective (see examples (13)-(14)). ${ }^{4}$

(13) Grammatical stimuli

a. Per questo le ho regalato un cappello for this her have.I offered a hat triangolare. $\quad(\mathrm{N}-\mathrm{Adj})$ triangular "This is why I offered her a triangular hat."

b. Ha fatto carriera in fretta. Questo has made career quickly this alto ufficiale high officer ha solo 25 anni. has only 25 years "He had a quick career. This high officer has only 25 years."

(14) Ungrammatical stimuli

a. *Per curare la sua anemia, Paola

to cure the his anemia Paolo

va spesso

goes often

in montagna alta.

to mountains high

"To cure his anemia, Paolo often goes to the high mountains."

b. *Per questo gli ho regalato una for this him have.I offered a corta cravatta. (Adj-N) short tie "This is why I offered him a short tie."

The stimuli differed in terms of three further properties: contextualization, complexity, and variability of placement. The items were not balanced with regard to these properties. ${ }^{5}$

First, some test sentences $(n=20)$ were preceded by a context sentence, but this sentence was only sometimes

${ }^{4}$ For simplification purposes, the notion of "grammaticality" is used here, but some sentences could be considered infelicitous rather than ungrammatical.

5 The number of contextualized test sentences, complex DPs, and variable adjectives was the same with respect to grammatical and ungrammatical stimuli. The number pre- and postnominal adjectives was slightly unbalanced with respect to grammaticality: postnominal adjectives were presented as grammatical more often, because they are more frequent in naturalistic speech in Italian (see above). 
relevant for the position of the adjective. For example, it is relevant in $(15 \mathrm{a})$ because povero "poor" can occur pre- and postnominally, depending on its meaning (see (3) above). In (15b), it is not relevant because nationality adjectives can only appear after the noun, regardless of context (but see (9) above). ${ }^{6}$

(15) a. Ha ereditato ma è rimasto orfano. has.he inherited but is remained orphan *Questo ragazzo povero mi fa pena. this boy poor me makes pain "He has inherited but he remained an orphan. I feel sorry for this poor boy."

b. Pietro ha vissuto a lungo in Inghilterra. Pietro has lived for long in Britain ${ }^{*} \mathrm{Ha}$ un'inglese fidanzata. has.he an English girlfriend "Pietro has been living in Britain for a long time. He has an English girlfriend."

Second, some items were syntactically more complex $(n=10)$ in that the adjective was modified, as in $(16 a)$, or coordinated, as in (16b). (Note that in this case complexity is not defined in terms of syntactic movement, but it terms of syntactic heaviness of the DP.)

(16) a. Ken Follett ha scritto di nuovo un libro Ken Follett has written again a book troppo lungo.

too long

"Ken Follett has written again a book that is too long."

b. *Oggi Pietro ha comprato una bella today Pietro has bought a nice gialla sciarpa. yellow scarf "Today Pietro bought a nice yellow scarf."

Finally, stimuli differed in terms of whether adjectives had one prevalent position, like adjectives of nationality, color and shape, or whether they showed variable placement, like value and size adjectives. The category of variable adjectives also included adjectives as part of semi-fixed or fixed expressions, such as alla buon'ora "at the right time". 7

${ }^{6}$ Context sentences were added inconsistently, because the test was relatively long and they were not always needed. The reason for adding context also where it was NOT needed was to prevent participants from linking contextualization and context-dependency of the adjective position. Contextualization could have affected performance, because adding context increases the length of the stimuli, thereby increasing processing demands.

7 This could be considered a problem had the only purpose been to test whether participants know the rules governing adjective placement.
As mentioned above, participants were asked to provide a repetition or correction depending on their judgment of the test sentence. The repetitions and corrections were used to examine whether subjects are responding relevantly. For example, reversal of the noun and the adjective in una corta cravatta counted as relevant, because it suggests sensitivity to adjective order. Corrections which failed to eliminate the relevant violations, as in un corto cravatto, where the gender of the DP has been changed, were treated as if no correction had been made. Instances in which participants did not respond in the given time were removed from the analysis ( $n=6$ for the Italian strong group, and $n=7$ for the Italian weak group). Corrections eliminating the relevant adjective-noun string were also removed $(n=8$ for the Italian weak group).

\section{Results}

Table 3 below shows the results by number of appropriate (i.e. target-like) responses from the total of responses included in the analysis. After establishing the overall rate of appropriate responses, five additional analyses were done to find out whether (i) grammaticality, (ii) ordering, (iii) contextualization, (iv) complexity and (v) variability determined the results. For each of these analyses, a multilevel logistic regression analysis was carried out. ${ }^{8}$ Heritage status (group) was always included in this analysis, and so were participants and items as random predictors.

The overall comparison shows that the heritage speakers of Italian chose the inappropriate order more often than the 2L1s with Italian as their stronger language. The difference was statistically significant $(\mathrm{B}=-3.47$, $\mathrm{SE}=0.85, \mathrm{z}=-4.07, p=.00)$. The next analysis investigated whether performance was dependent on the grammaticality of the stimulus sentence. Since the $2 \mathrm{~L} 1 \mathrm{~s}$ with Italian as stronger language performed at ceiling ( $100 \%$ accuracy), this analysis could only be done for the Italian heritage speakers. These performed significantly better in repeating grammatical stimuli than in correcting ungrammatical ones $(\mathrm{B}=3.18, \mathrm{SE}=0.64, \mathrm{z}=4.97, p=$ $.00)$. By contrast, neither ordering $(\mathrm{B}=-1.36, \mathrm{SE}=0.84$, $\mathrm{z}=-1.61, p=.11)$, nor contextualization $(\mathrm{B}=1.06, \mathrm{SE}$ $=0.84, \mathrm{z}=1.26, p=.21)$, nor complexity $(\mathrm{B}=0.54$, $\mathrm{SE}=1.01, \mathrm{z}=0.53, p=.60)$ had a significant effect on performance. There was no significant interaction between these predictors and the group factor either ( $\mathrm{B}=0.27, \mathrm{SE}=0.93, \mathrm{z}=0.29, p=.78$ for ordering, $\mathrm{B}=-0.45, \mathrm{SE}=1.04, \mathrm{z}=-0.43, p=.67$ for

However, another goal was to find out which strategy bilinguals pursue when they do not know the rules.

8 Ideally, a single regression analysis should have been carried out. The motivation for separate analyses was that the number of predictors becomes large in comparison to the number of cases. 
Table 3. Appropriate responses (in \%) in Italian as weaker and as stronger language (experimental data), overall and according to predictors.

\begin{tabular}{llll}
\hline \hline & & 2L1 strong Italian $(\mathrm{n}=8)$ & 2L1 weak Italian $(\mathrm{n}=10)$ \\
\hline & Overall responses $(\mathrm{n}=44)$ & $337 / 346(97.4 \%)$ & $388 / 470(82.6 \%)$ \\
(i) & Grammatical $(\mathrm{n}=22)$ & $173 / 173(100 \%)$ & $227 / 238(95.4 \%)$ \\
& Ungrammatical $(\mathrm{n}=22)$ & $164 / 173(94.8 \%)$ & $161 / 232(69.5 \%)$ \\
(ii) $^{*}$ & Adj-N order $(\mathrm{n}=22)$ & $167 / 172(97.1 \%)$ & $190 / 237(80.2 \%)$ \\
& N-Adj order $(\mathrm{n}=21)$ & $162 / 166(97.6 \%)$ & $187 / 222(84.2 \%)$ \\
(iii) & With context $(\mathrm{n}=20)$ & $155 / 157(98.7 \%)$ & $187 / 217(86.2 \%)$ \\
& Without context $(\mathrm{n}=24)$ & $182 / 189(96.3 \%)$ & $201 / 253(79.4 \%)$ \\
(iv) & Complex $(\mathrm{n}=10)$ & $77 / 79(97.5 \%)$ & $86 / 107(80.4 \%)$ \\
& Simple $(\mathrm{n}=34)$ & $260 / 267(97.4 \%)$ & $302 / 363(83.2 \%)$ \\
(v) & Variable adjective $(\mathrm{n}=23)$ & $173 / 178(97.2 \%)$ & $181 / 241(75.1 \%)$ \\
& Invariable adjective $(\mathrm{n}=20)$ & $156 / 160(96.5 \%)$ & $196 / 218(89.9 \%)$ \\
\hline \hline
\end{tabular}

* One item was excluded because it contained a combination of a pre- and a postnominal as well as a variable and an invariable adjective.

contextualization, and $\mathrm{B}=-0.58, \mathrm{SE}=1.18, \mathrm{z}=-0.50$, $p=.62$ for complexity). Finally, although performance was better with adjectives having an invariable order than with adjectives having variable orders, the difference was not significant $(\mathrm{B}=-1.19, \mathrm{SE}=0.78, \mathrm{z}=-1.53, p=$ $.13)$, and there was no interaction between variability and group either $(\mathrm{B}=-1.24, \mathrm{SE}=0.93, \mathrm{z}=-1.33, p=$ .18). In summary, the $2 \mathrm{~L} 1 \mathrm{~s}$ with Italian as their stronger language performed significantly better than the heritage speakers, but only the grammaticality of the stimuli had a significant impact on overall performance.

The absence of a significant effect of ordering was surprising, because any account of CLI predicts the overacceptance of prenominal adjective placement, given the overlap with the German structure and its less costly syntactic derivation. Ordering was therefore analyzed once more, this time for grammatical and ungrammatical items separately. Figure 1 illustrates the number of corrections in each condition.

Figure 1 shows that when being presented with an ungrammatical stimulus, 2L1 speakers were more

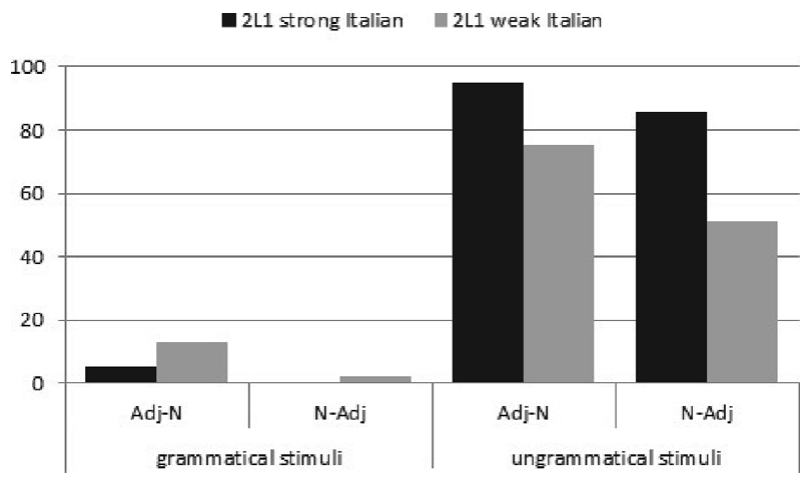

Figure 1. Frequency of corrections (\%) with pre- and postnominal adjectives. successful in correcting Adj-N orders than $\mathrm{N}$-Adj orders. In other words, missing (though required) corrections were more typical when the adjective was postnominal, as in (17) (see (14a) above for another item which often failed to be corrected).

\section{(17) Example of missing correction}

${ }^{*} \mathrm{Ha}$ ereditato ma è rimasto orfano. has inherited but is remained orphan

Questo ragazzo povero mi fa pena. this boy poor me makes pain "He inherited but remained an orphan. I'm sorry for this poor boy."

Vice versa, when being presented with grammatical stimuli, where NO correction was required, participants were more inclined to reverse Adj-N strings. For example, in (18), where the Adj-N order would have been appropriate with the given context, some participants changed povero ragazzo "unfortunate/poor boy" to ragazzo povero (see (13b) for another $\mathrm{Adj}-\mathrm{N}$ item, which was often reverted to $\mathrm{N}-\mathrm{Adj}$ ).

\section{(18) Example of inappropriate correction \\ ${ }^{*} \mathrm{Ha}$ perso da poco i genitori. has lost recently the parents this}

Questo ragazzo povero $\mathrm{mi}$ fa pena. this boy poor me makes pain "He recently lost his parents. I'm sorry for this poor boy."

A multilevel regression analysis for the $2 \mathrm{~L} 1 \mathrm{~s}$ with Italian as the weaker language confirms that the difference between grammatical and ungrammatical stimuli is not the same for postnominal adjectives as for prenominal adjectives $(\mathrm{B}=3.53, \mathrm{SE}=0.80, \mathrm{z}=4.43, p=.00)$. The correction patterns thus point to a general preference of the postnominal order. 


\section{Discussion and conclusions}

\subsection{Summary}

Italian adjectives show variation in their position with respect to the noun, which is sometimes contextually conditioned. Their syntactic derivation is also variable, and it may involve the left periphery of the DP - a domain that is generally considered "vulnerable". Adjective placement in Italian is superficially similar to adjective placement in German but, arguably, syntactically more complex. These properties match the preconditions for the occurrence of CLI defined in previous work, and, indeed, DEVELOPMENTAL studies found overuse of prenominal adjectives when Italian was acquired simultaneously with German.

The present study addressed the question whether adult Italian bilinguals overuse adjectives prenominally, similar to bilingual children. Speakers who have acquired Italian in Italy were compared with speakers who have acquired Italian in Germany to uncover potential differences between Italian as a stronger language and Italian as a heritage (weaker) language.

Finally, performance in naturalistic speech was compared to performance in a timed AJT.

\subsection{Developing and end-state grammars}

When comparing the results of the present study to studies on adjective placement in bilingual Italianlearning children, specifically Bernardini (2003) and Rizzi et al. (2013), it must be kept in mind that the two aforementioned studies were based on naturalistic data. They are thus comparable to the first part of the present study, which showed a very low error rate and no contrast between the two groups of bilinguals, indicating that nontargetlike structures in bilingual development disappear over time. In the AJT, on the other hand, the heritage speakers of Italian produced a significantly higher number of non-targetlike responses than the $2 \mathrm{~L} 1 \mathrm{~s}$ with Italian as their stronger language. Unlike bilingual children, they were more likely to overuse the POSTNOMINAL position.

It thus appears as if developing bilinguals and adults did not have the same placement preferences: Children opt for the syntactically more economical solution, which is present in both languages, while adults are not affected by complexity, overstressing contrasts between languages.

This tentative conclusion receives support from a study comparing placement preferences in English-Norwegian children and adults (Anderssen \& Westergaard, 2012). Norwegian has two ways of expressing possession. For example, both min bil "my car" and bil-en min "car-the my" translate into "my car". The construction with the prenominal possessor is syntactically less complex and less frequent in Norwegian. Anderssen and Westergaard
(2012) have shown that children overuse the syntactically less complex construction with prenominal possessives, while adult heritage speakers are more inclined to use the more frequent and syntactically more complex construction with postnominal possessives.

\subsection{Italian as the weaker and as the stronger language}

The two groups of bilinguals in the present study did not differ in the amount of placement errors in spontaneous data, but there were several other differences.

First, the $2 \mathrm{~L} 1 \mathrm{~s}$ with Italian as their stronger language had a lower type-token ratio for pre- and postnominal adjectives, suggesting that the different input conditions during acquisition - i.e. acquisition of Italian in Italy vs. acquisition of Italian in Germany - affected the size of the lexicon.

Second, the 2L1s from Italy produced fewer nontargetlike responses in the AJT. Thus, the different input conditions during childhood and adolescence also determined how closely the $2 \mathrm{~L} 1$ speakers reflected the placement preferences of monolingual native speakers. There were individual exceptions in each of the two groups, which raises the question whether these could be related to language use at the time of testing. Recall that one participant grew up in Italy but moved to Germany as an adult. In fact, among the $2 \mathrm{~L} 1 \mathrm{~s}$ who grew up in Italy, he produced the highest number of target-deviant responses. In contrast, however, the heritage speakers of Italian with the most target-like performance were not all frequent users of Italian.

Third, unlike the $2 \mathrm{~L} 1 \mathrm{~s}$ from Italy, the heritage speakers of Italian performed better with adjectives whose placement was invariable than with adjectives whose placement was variable (see (v) in Table 3 ) above. Although the contrast was not significant, it could point to problems with interfaces, because for adjectives with variable positions it is more important to integrate contextual information.

\subsection{Naturalistic and experimental data}

Performance (measured in terms of native speaker expectations) differed between naturalistic and experimental data. Both groups of bilinguals were native-like with respect to adjective placement in naturalistic speech. The near absence of inappropriate placement in this kind of data may be related to the fact that speakers are free to choose their topics and can thus avoid using constructions they are not familiar with. In the AJT, where the position of adjectives had to be corrected under time pressure, the heritage speakers committed a higher number of placement errors and showed a stronger inclination to use the postnominal position. Here, they may have been 
confronted with sentences that they would not have used spontaneously.

The heritage speakers' overacceptance and overuse of the postnominal position is unexpected given standard assumptions in the literature. Previous accounts on CLI (e.g. Döpke, 1998; Müller, 1998) suggest that when the structures of the target language overlap partially, bilinguals will overuse what is common to both languages, but the participants in this study did the reverse. Possibly, their behavior results from some awareness about what is common and what is different in their two languages. Specifically, they may know that the postnominal position is more typical for Italian than the prenominal position, and this is why, in cases of uncertainty, they are more inclined to produce it - a pattern that could be described in terms of CROSS-LINGUISTIC OVERCORRECTION (CLO), as opposed to CLI. Put simply: bilinguals exaggerate the contrasts rather than the similarities between their two languages.

The idea advanced here may appear to contradict previous proposals on $2 \mathrm{~L} 1$ behavior. Specifically, Montrul (2009) proposed that, compared to L2 speakers, bilinguals have a disadvantage in tasks requiring extra-linguistic knowledge, such as GJTs, because L2ers, but not early bilinguals, tend to access extra-linguistic knowledge. The view that overuse and acceptance of the postnominal position could result from linguistic awareness appears to run counter to Montrul's assumption. But perhaps the two views can be reconciled: L2ers have an advantage over early bilinguals in tasks giving them sufficient time to think about what they have learnt about some linguistic property (EXPLICIT extra-linguistic knowledge). Instead, performance under time-pressure may reveal IMPLICIT extra-linguistic knowledge. ${ }^{9}$

Concededly, the idea of cross-linguistic overcorrection can only be tentative, as it is based on an experiment in which the stimuli were not optimally balanced. Ideally, the study should be repeated with a more balanced distribution of stimuli, whose selection is motivated by occurrences in the spontaneous speech of Italian heritage speakers. It could further include a think-aloud protocol in which subjects try to explain their choices.

\subsection{Modeling cross-linguistic overcorrection}

The data presented here lend support to Nicoladis' (2006) idea that variable adjective placement in bilinguals can

9 An anonymous reviewer notes that time pressure was not too severe in the task presented here. Admittedly, the given time was very long for the 2L1s strong Italian group, but it was just right or sometimes even too short for the heritage speakers. Note that responses in which the last part of the sentence was missing were included, provided that the adjective-noun string was intact. be conceived as a manifestation of speech production errors. The model outlined in Nicoladis (2006), which is adopted here with minor changes, was inspired by the speech production models in Costa (2004), Dell, Chang and Griffin (1999), Ferreira and Dell (2000), among others. Accordingly, there are three phases in speech production. During the first phase, the speaker represents the message he wishes to convey, i.e. the nonverbal concepts and their interactions. During the second phase, the lemma stage (Ferreira \& Dell, 2000), the speaker chooses the words and the syntactic structure in which these words will appear. If there are multiple syntactic frameworks which could convey a similar message, these frameworks will compete, which may result in speech errors. During the third phase, the phonological frame is chosen.

It is the lemma stage that is relevant for the occurrence of CLO. Lemmas encode the information that is needed to construct the syntactic structure of a sentence. When a bilingual speaker selects the syntactic framework, he must choose words from the appropriate language and the appropriate syntactic frame. If there are several options with the potential to convey similar meanings, these will be in competition. Options that are not chosen remain activated, albeit to a lesser degree. In the case illustrated here, the syntactic frame for German $(\operatorname{Adj}-\mathrm{N})$ will compete with the Italian $\mathrm{N}-\mathrm{Adj}$ frame. For example, when choosing the concepts "dog" and "poor" in order to produce a German utterance, both the corresponding Italian and German lexemes will be activated. The German lexemes will be more active because German is the target language. Similarly, when the German syntactic frame Adj- $\mathrm{N}$ is chosen, the predominant Italian frame, $\mathrm{N}-\mathrm{Adj}$, will be co-activated, albeit to a lesser extent. Under the assumption that more frequent structures are always coactivated, we are now in a position to explain why in the case of speech production errors in Italian, $\mathrm{N}$-Adj is more likely to be chosen than Adj-N. The reason is that N-Adj, being more frequent, will always be co-activated, even when Adj- $\mathrm{N}$ is the target.

Figure 2 below illustrates a schematic diagram of the activation to produce povero cane "poor dog". The representation of the concepts activates the corresponding Italian and German lexemes (the latter are less active, as indicated by dotted lines) and the corresponding syntactic frames. The frame Adj- $\mathrm{N}$ is very active, as it is the one being selected, but $\mathrm{N}-\mathrm{Adj}$ is also active, even though it is not being selected, because it occurs with higher frequency in Italian. Given its higher activation in the language, NAdj is more likely to be chosen when $\mathrm{Adj}-\mathrm{N}$ is required than vice versa.

The model also poses new questions. One question is why bilingual children acquiring a Romance language overuse prenominal adjectives at all. The other question is why co-activation of Italian Adj-N and German 


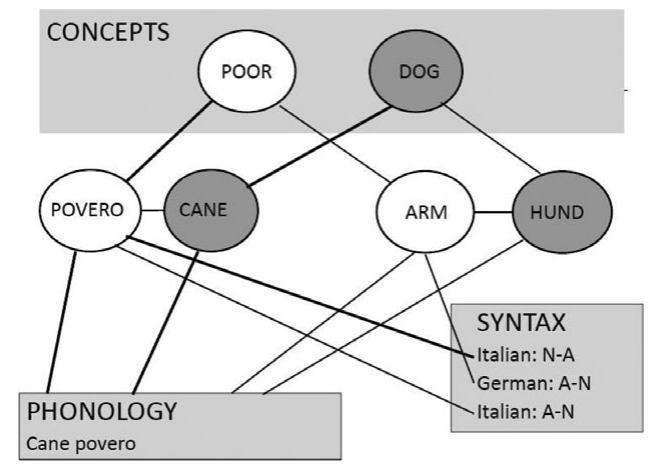

Figure 2. Activation scheme for povero cane.

Adj-N together does not override $\mathrm{N}-\mathrm{Adj}$. A possible answer to the latter question may be that co-activation strength is different for competing structures within and across languages. Specifically, the weight of the coactivated German structure could be so low that even in combination with Italian Adj-N it will not affect Adj-N.

Put differently, it may be easier to demote competing structures in the "other" language than competing structures in the target language. Furthermore - and this could be the answer to the first question - speakers' ability to demote the other language may increase with growing age and language awareness, which would explain why bilingual CHILDREN acquiring a Romance language have a greater tendency towards overusing Adj$\mathrm{N}$ than ADULTS. ${ }^{10}$

Finally, in addition to their ability to demote the language that is not the target in a particular setting, adult 2L1 speakers may have a higher awareness of languagespecific rules than monolingual and child $2 \mathrm{~L} 1$ speakers, due to longstanding experience in using their two languages daily and in similar or even the same contexts. Unlike for L2 learners who have rule-based extralinguistic knowledge of their L2, the 2L1s' knowledge is normally not based on explicit instruction and thus IMPLICIT.

\section{Conclusions}

The results of this study suggest that comparative differences in input and use of a language can, but need not, result in divergent competences of bilinguals. It was shown that some instances of variation in bilingual grammars are not an effect of cross-linguistic influence. The data presented indicate that bilingual adults sometimes overstress contrasts (cross-linguistic

\footnotetext{
${ }^{10}$ Another question is whether the idea of different syntactic derivations for one and the same surface structure can be integrated into the model.
}

overcorrection) rather than similarities between two languages; in doing so, they may opt for the syntactically more complex structure. In both these respects, they differ from bilingual children. Future research should further specify the conditions under which overcorrection occurs.

\section{References}

Anderssen, M., \& Westergaard, M. (2012). Vulnerable domains in Norwegian heritage language: Word order and definiteness within the DP? Presented at the 3rd Workshop on Immigrant Languages in America, Pennsylvania State University.

Bernardini, P. (2003). Child and adult acquisition of word order. In N. Müller (ed.), (In)vulnerable domains, pp. 41-84. Amsterdam: John Benjamins.

Cardinaletti, A., \& Giusti, G. (2010). The acquisition of adjectival ordering in Italian. In M. Anderssen, K. Bentzen \& M. Westergaard (eds.), Variation in the input, pp. 65-93. Dordrecht: Springer.

Cinque, G. (1994). On the evidence for partial $\mathrm{N}$ movement in the Romance DP. In G. Cinque, J. Koster, J.-Y. Pollock, L. Rizzi \& R. Zanuttini (eds.), Paths towards universal grammar: Studies in honour of Richard S. Kayne, pp. 85110. Washington, DC: Georgetown University Press

Cinque, G. (2010). The syntax of adjectives: A comparative study (Linguistic Inquiry Monographs). Cambridge, MA: MIT Press.

Costa, A. (2004). Speech production in bilinguals. In T. K. Bhatia \& W. C. Ritchie (eds.), The handbook of bilingualism, pp. 201-223. Malden, MA: Blackwell.

Dell, G. S., Chang, F., \& Griffin, Z. M. (1999). Connectionist models of language production: Lexical access and grammatical encoding. Cognitive Science, 23, 517-542.

Döpke, S. (1998). Competing language structures: The acquisition of verb placement by bilingual German-English children. Journal of Child Language, 25, 555-584.

Ferreira, V. S., \& Dell, G. S. (2000). Effect of ambiguity and lexical availability on syntactic and lexical production. Cognitive Psychology, 40, 296-340.

Giusti, G. (2006). Parallels in clausal and nominal periphery. In M. Frascarelli (ed.), Phases of interpretion, pp. 163-184. Berlin: Mouton.

Hulk, A., \& Müller, N. (2000). Cross-linguistic influence at the interface between syntax and pragmatics. Bilingualism: Language and Cognition, 3, 227-244.

Jakubowicz, C. (2002). Functional categories in (ab)normal language acquisition. In I. Lasser (ed.), The process of language acquisition, pp. 165-202. Frankfurt am Main: Lang.

Kupisch, T. (2007). Determiners in bilingual German-Italian children: What they tell us about the relation between language influence and language dominance. Bilingualism: Language and Cognition, 10, 57-78.

Kupisch, T. (2012). Generic subjects in the Italian of early German-Italian bilinguals and German learners of Italian as a second language. Bilingualism: Language and Cognition, 15, 736-756. 
Kupisch, T., Barton, D., Bianchi, G., \& Stangen, I. (2012). The HABLA-Corpus (German- French and German-Italian). In T. Schmidt \& K. Wörner (eds.), Multilingual corpora and multilingual corpus analysis, pp. 63-79. Amsterdam: John Benjamins.

Montrul, S. (2009). Reexamining the Fundamental Difference Hypothesis: What can early bilinguals tell us? Studies in Second Language Acquisition, 31, 225-257.

Montrul, S., \& Ionin, T. (2010). Transfer effects in the interpretation of definite articles by Spanish heritage speakers. Bilingualism: Language and Cognition, 13, 449473.

Müller, N. (1998). Transfer in bilingual first language acquisition. Bilingualism: Language and Cognition, 1, 151-171.

Nicoladis, E. (2006). Cross-linguistic transfer in adjectivenoun strings by preschool bilingual children. Bilingualism: Language and Cognition, 9, 15-32.

Rizzi, S., Arnaus Gil, L., Repetto, V., Müller, J., \& Müller, N. (2013). Adjective placement in bilingual RomanceRomance and Romance-German children with special reference to Romance (French, Italian and German). Studia Linguistica, 67, 123-147.
Rothman, J. (2009). Understanding the nature of early bilingualism: Romance languages as heritage languages. International Journal of Bilingualism, 13, 155-163.

Serratrice, L., Sorace, A., Filiaci, F., \& Baldo, M. (2009). Bilingual children's sensitivity to specificity and genericity: Evidence from metalinguistic awareness. Bilingualism: Language and Cognition, 12, 239-257.

Sorace, A. (2011). Pinning down the concept of "interface" in bilingualism. Linguistic Approaches to Bilingualism, 1, 133.

Sorace, A., \& Serratrice, L. (2009). Internal and external interfaces in bilingual language development: Beyond structural overlap. International Journal of Bilingualism, 13, 1-16.

Strik, N., \& Pérez-Leroux, A. (2011). Jij doe wat girafe? Whmovement and inversion in Dutch-French bilingual children. Linguistics Approaches to Bilingualism, 1, 175-205.

Volterra, V., \& Taeschner, T. (1978). The acquisition and development of language by bilingual children. Journal of Child Language, 5, 311-326.

Yip, V., \& Matthews, S. (2007). The bilingual child: Early development and language contact. Cambridge: Cambridge University Press. 